\title{
FENOMENOLOGÍA DEL CUERPO HUMANO ${ }^{1}$
}

\author{
Miguel Ángel Villamil Pineda \\ Universidad Santo Tomás
}

Recibido: marzo 2 de 2005

Aprobado: mayo 6 de 2005

\section{Resumen}

Uno de los problemas fundamentales planteados por la ciencia y la filosofía occidental es el que se refiere al ser del hombre. Las respuestas dadas a este problema han girado alrededor de concepciones idealistas y materialistas. La fenomenología nos pone de presente que estas representaciones, al radicalizar sus posturas, resultan insuficientes, ya que, por dar prioridad al cuerpo o a la subjetividad, destotalizan la unidad integral del ser humano. La experiencia nos muestra al hombre como un ser corporal unitario que se manifiesta como: expresión de una subjetividad; vía de acceso al mundo de las cosas; "punto cero" de todas las experiencias; órgano transformador de la realidad; órgano de socialización; órgano axiológico. Además, el hombre tiene la posibilidad de reflexionar, es decir, de volver sobre las experiencias corporales. Así, podemos ver que la experiencia corporal y la experiencia reflexiva son los dos modos de ser fundamentales de una misma constitución humana. No "tenemos" un cuerpo, somos cuerpo; no pensamos "desde" el cuerpo, ni "a través" del cuerpo, pensamos como cuerpo, pensamos corporalmente.

\section{Palabras clave}

Fenomenología, ser del hombre, cuerpo, experiencia, reflexión

\begin{abstract}
One of the fundamental problems set up by the science and the western philosophy is that of the human being. The answers given to this problem have gone round idealistic and
\end{abstract}

1 Esta es una síntesis de una investigación mediante el método fenomenológico sobre el sentido del cuerpo. 
materialistic understandings. The phenomenology puts us in mind that these representations, as they harden their stances, result insufficient because the stress they put on the body or on subjectivity dismantle the human being complete unity. The experience shows us the human being as a corporeal unity being that is revealed as: expression of subjectivity; the way of access to the world of things; 'zero point' of all experiences; the trasforming organ of reality; the socializing organ; the axiologic organ. Moreover, the human being has the faculty to think over, that is, to go back on the corporeal experiences. In this way, we can see that the corporeal and the reflective experiences are the two fundamental modes of the same human constitution. We don't 'have' a body, we are body, we don't think 'from' the body, neither 'through' the body, we think as a body, we think in a bodily form.

\section{Key words}

Phenomenology, human being, body, experience, reflection

\section{Introducción}

La percepción es un proceso cultural de aprendizaje. La tarea de aprender a percibir debe hacerse más pronto que tarde porque en aprender a percibir se nos va la vida.

La filosofía occidental ha considerado que uno de los problemas fundamentales, al cual debe responder el filósofo, es el que se refiere al ser del hombre. De la respuesta a esta pregunta dependen las concernientes al origen y estructura de su naturaleza, a los alcances del conocimiento humano, a la vocación axiológica del hombre, a la intersubjetividad y las consecuencias de ésta.

Pero, ¿cuál ha sido la respuesta a la pregunta sobre el ser del hombre? Han sido múltiples, y la mayoría de ellas han girado alrededor de visiones reduccionistas, ya sean espiritualistas o materialistas.

La visión espiritualista es dualista y define al hombre como un ser compuesto de cuerpo y alma (razón, mente o espíritu). Dentro de esta visión, con mayor frecuencia, el cuer- po ha sido denigrado como un objeto indeseable, como fuente de error, como una realidad a soportar, como un aspecto; en suma, como un "algo" ajeno al ser humano. La función esencial del alma sería la de humanizar el cuerpo, y sólo en la medida en que lo logre, ese cuerpo se diferenciaría de otros cuerpos meramente zoológicos.

La visión materialista es monista y define al hombre como un organismo biológico. En los últimos tiempos, bajo el imperio del positivismo, sobre todo el de médicos y biólogos, el hombre ha llegado a ser definido sólo a partir de su materialidad. De esta manera, el "alma" pasa a ser concebida como la función de un cerebro humano más desarrollado. El comportamiento -pensamiento, libertad, intencionalidad, sentimientos, emociones, personalidad- es explicado sólo como efecto de relaciones físico-químicas llevadas a cabo en el cuerpo humano.

La fenomenología, en su conjunto, se opone tanto a la visión dualista como a la materialista, y afirma, en un sentido totalmente diferente, que el hombre es una corporeidadsubjetivada, una conciencia-encarnada. De 
acuerdo con esto, considera que la conciencia "pura" no es el origen y fundamento del pensar, y que la constitución del mundo y del otro no tiene el signo de la idea, sino de una operación corporal, que, como el cogito cartesiano, conoce, quiere, desea, imagina, siente. La percepción, o conciencia irreflexiva, es el diálogo de la vida con su mundo y con el otro; diálogo que implica la palabra, el gesto, la significación, el sentido. El pensar reflexivo que nos permite la representación cognoscitiva, valorativa, sensitiva y afectiva acompaña a la percepción porque el cuerpo tiene la posibilidad de reflexionar3 sobre sí, es decir, de volver sobre sus vivencias, sus experiencias de mundo y del otro. La percepción y la reflexión son las dos caras del constituir corporal.

El sostén material del comportamiento humano efectivamente está formado por las estructuras espacio-temporales de las células nerviosas, pero la fenomenología afirma que dicha materialidad no define el ser del hombre en sentido estricto. El cuerpo está constituido por la materia, pero la subjetividad, es decir, su ser personal, es el principio de organización de dicha materia. A pesar de su supercerebro, el hombre no sería un ser personal capaz de decidir por sí mismo si su principio ordenador de la materia no fuera una verdadera subjetividad.

Tanto el espiritualismo como el materialismo, al radicalizar sus posturas, destotalizan la realidad de la existencia humana, la cual se nos muestra como una unidad integral en el mundo de la vida. La fenomenología, lejos de divorciar cuerpo y subjetividad, trata de explicitar dicha unidad integral concibiendo el cuerpo humano como la expresión de una subjetividad: espíritu encarnado (Merleau-Ponty), libertad situada (Sartre), ser-en-el-mundo (Heidegger), corporeidad anímica (Zubiri), vida que experimenta el mundo (Husserl).

Antes de exponer en detalle la visión fenomenológica, veamos algunas de las visiones reduccionistas.

\section{Visiones reduccionistas acerca del ser del hombre}

\section{1 ¿Es el cuerpo una cárcel o una tumba para el alma?}

Para Platón el hombre es alma y cuerpo, pero el cuerpo es considerado cárcel y tumba del alma. El alma, como miembro del mundo de las ideas tiene por misión liberarse del cuerpo y volver a su existencia espiritual. Lo espiritual es la verdadera realidad. De aquí que Platón afirme rotundamente que "el hombre es su alma"².

Para Agustín, como filósofo, el hombre es esencialmente alma: "el alma es un alma racional que se sirve de un cuerpo"'3. Dado su platonismo y su pasaje por el maniqueísmo, no es de extrañar que Agustín asumiera posturas muy negativas frente al cuerpo y a todo aquello que tiene asiento en él, como el sexo, por ejemplo.

En estos dos autores, el alma, que se servía del cuerpo para experimentar el mundo, es separada y concebida en un mundo autónomo. Esta separación se debe a que, en aras de construir un conocimiento netamente objetivo, no se problematiza el fundamento de las ideas y, por tanto, no se llega a descubrir al cuerpo como sujeto. El error radica en que la realidad del mundo fue suplantada por la realidad de la idea. La idea no es subsistente en sí misma; ella siempre se alimenta del

Platón, Alcibiades, I. 130; Fedro, 247c.

3 Agustín, De mor. Eccl. Et manich, I, 27, 52. 
mundo real experimentado por el cuerpo. La idea es expresión subjetiva de la esencia de la realidad. Platón no la concibe así, sino como una especie de "ego divino" ante el cual la corporeidad humana pierde su consistencia.

\section{$1.2 ¿$ Es el cuerpo humano animal?}

Aristóteles concibe al hombre como un compuesto de materia y forma: "cuerpo es materia y el alma es su forma”4. El alma es el principio que constituye en viviente al cuerpo. Cuerpo y alma unidos substancialmente forman al hombre. El alma es, ante todo, razón. Esto lleva a Aristóteles a definir al hombre partiendo de la dimensión zoológica: animal racional, animal político. Lo racional es la diferencia específica que tiene como función humanizar la animalidad. Las propiedades individuales, tan esenciales al ser personal, no tienen importancia porque por medio de la lógica quedan reducidas a meros accidentes. Esta concepción llevó a Aristóteles a definir a las mujeres como "varones accidentados”, casos fallidos de la naturaleza esencial $^{5}$. Para este autor, habría que excluir de la especie humana a los esclavos, quienes no son animados y, por lo mismo, pertenecen totalmente a sus dueños ${ }^{6}$.

Tomás de Aquino profundizó el pensamiento de Aristóteles. Nos dice que "de la unión substancial de cuerpo y alma resulta el hom-

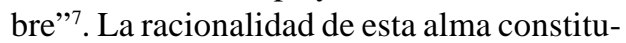
ye la diferencia específica en la definición de hombre, esto es, animal racional.

Concebir al hombre a partir de la animalidad es una visión ingenua, ya que en el hombre nos encontramos con un proyecto absolutamente único. La corporeidad humana es una realidad original y esencialmente diferente a la de los demás seres vivos. Los sentidos humanos no son como los sentidos de los animales; no están determinados por la naturaleza, sino abiertos al mundo. En virtud de esta apertura sensorial podemos y debemos crear cultura. La no especialización del cuerpo humano nos impulsa a transformar el mundo según nuestras intenciones y necesidades.

Desde un enfoque negativo, tenemos que reconocer que los órganos y sentidos animales son más perfectos y están estrictamente adecuados a las exigencias y condiciones de su vida. El animal posee una especie de ley natural que prescribe su comportamiento en cada situación. Comparado con el animal, el hombre aparece como el hijo más huérfano de la naturaleza: desnudo e inerme, débil y pobre, tímido y desarmado; y lo que acrecienta la suma de su desgracia, desprovisto de toda guía de la vida. El carácter natural de la raza humana consiste en fallas y carencias $^{8}$. Dentro de la escala animal, el hombre es un ser necesitado que ocupa uno de los lugares más bajos: le falta revestimiento de pelo, órganos de ataque, formación apropiada para la huida. Además, es superado por la mayoría de los animales en la agudeza de los sentidos. En el mundo animal, el hombre tiene una carencia mortalmente peligrosa, lo cual hubiese provocado su rápida extinción.

Desde un enfoque positivo, debemos afirmar que el hombre, desde el principio, es un ser capaz de experimentar, transformar y dominar la naturaleza ${ }^{9}$. El hombre es el primer liberto de la naturaleza, está organizado para

\footnotetext{
Aristóteles, De anima, L.II, c. I, 412a , 414b.

Cf. Aristóteles, De la generación de los animales, II, 3, 737a.

Cf. Aristóteles, Política. I, 2, 1253b.

Santo Tomás de Aquino, Summa Theologica, I, 77, 2.

Cf. Michel Landmann, Antropología filosófica, trad. Carlos Moreno (México: Uteha, 1961).

Cf. Arnold Gehlen, El hombre: Su naturaleza y su lugar en el mundo (Salamanca: Sígueme, 1987) 8-10.
} 
la libertad. No es una máquina infalible en manos de la naturaleza. Él se convierte a sí mismo en meta y objeto de su trabajo.

La no especialización natural significa una apreciable ventaja debido a que nuestros órganos no están adecuados a unos fines predeterminados, sino abiertos a metas y fines que podemos definir desde nosotros mismos. La corporeidad humana, al no estar gobernada por el instinto, sino a disposición de su subjetividad, puede aspirar a crear un mundo que rebase las fronteras deterministas del hábitat, esto es, el mundo cultural. Nuestra existencia puede hacerse más fácil gracias a nuestros inventos y estructuras sociales $y$, de esta manera, podemos incluso dominar al animal, aparentemente mejor equiparado para la sobrevivencia. Con respecto a la corporeidad subjetivada, el animal es tan sólo un ser de carencias, y el hombre es el ser que ocupa el puesto más alto entre todos los seres.

\section{3 ¿Es el cuerpo humano una máquina o una cosa?}

La filosofía moderna, a partir de Descartes, acentúa el dualismo. Cuerpo y alma son concebidos como dos realidades opuestas radicalmente. Para Descartes, en el universo sólo existen dos sustancias: pensamiento y extensión. El cuerpo pertenece al mundo de la extensión, y en su funcionamiento es asimilado a una simple máquina. En sí, el hombre es pensamiento: "hablando con precisión no soy más que una cosa que piensa, es decir, un espíritu, un entendimiento, una razón. ¿Qué soy entonces? Una cosa que piensa" ${ }^{10}$. "El yo, es decir, el alma por la que soy lo que soy, es enteramente distinta al cuerpo" ${ }^{11}$.
En este orden de ideas, el cuerpo es enteramente extraño al espíritu. Al ser definido como extensión, cae bajo los análisis cuantitativos realizados a las cosas. Así, Descartes inaugura la filosofía de la razón pura y deja las puertas abiertas para el advenimiento del positivismo, el cual tilda a la percepción de conocimiento oscuro y la reemplaza por el conocimiento claro de las matemáticas. El mundo comenzó a ser considerado como un mundo racional en sí, en el nuevo sentido de la racionalidad tomado de las matemáticas o de la naturaleza matematizada ${ }^{12}$.

Conocemos los esfuerzos de los racionalistas que trataron de explicar las innegables relaciones entre cuerpo y alma: el ocasionalismo de Malebranche, el monismo panteísta de Spinoza, la armonía preestablecida de Leibniz. Éste es también el cometido de la actual ciencia cognitiva, la cual intenta constituirse como una ciencia natural de la mente. Su propósito puede entenderse como el de la construcción de una teoría que permita elaborar explicaciones que sean aceptables para un enfoque naturalista de las propiedades de la mente. De este enfoque nace el computacionalismo y la inteligencia artificial. Éstos suponen que los procesos mentales son procesos algorítmicos de manipulación de símbolos que se realizan en un medio físico complejo -cerebros o computadores- gracias a la arquitectura funcional del sistema.

Los entusiastas de la inteligencia artificial consideran que el cuerpo es una máquina. Daniel Dennet ${ }^{13}$ afirma que la conciencia consiste en tener una máquina virtual como sistema de control. La conciencia viene sien-

Renato Descartes, Meditaciones metafísicas (Madrid: Alfaguara, 1977) 25-26.

11 Renato Descartes, Principia Philosophiae, I, 8.

12 Cf. Edmund Husserl, La crisis de las ciencias europeas y la fenomenología trascendental (Barcelona: Crítica, 1991) 14.

13 Cf. Daniel Dennett, Conciousness Explained (Boston: Little, Brown and Co. 1991). 
do como una gama amplia de actividades y habilidades. Al descomponer lo complejo podemos llegar a un nivel en donde las tareas se pueden hacer mecánicamente. Mecánicamente significa que un computador puede hacerlo, y si un computador puede, entonces la conciencia funciona como un mecanismo complejo de neuronas. Por consiguiente, la conciencia puede ser representada sintácticamente por un sistema formal en un computador.

Es cierto que muchas actividades de la conciencia pueden ser reproducidas mecánicamente, pero esto no nos garantiza que todas las actividades pertinentes puedan ser simuladas mecánicamente, o que no haya unos aspectos de la conciencia que puedan escapar al modelo computacional. Quizá las emociones son estados de conciencia que no son computacionales. ¿Podría amar un computador? Para responder afirmativamente esta pregunta tendríamos que reducir la intencionalidad del ser humano a la extencionalidad de su materialidad. El hecho de que algunos estados conscientes puedan ser representados por computaciones no significa que sean computaciones. La conciencia no actúa sólo sintácticamente sino, y sobre todo, semánticamente. Las formas, los mecanismos, las habilidades, las tareas son concebidas a partir del sentido, la significación, la intencionalidad, en suma, la subjetividad.

Las idealidades de la ciencia no sólo reenvían al mundo sensible a partir del cual han sido construidas, sino que su sentido depende totalmente de este mundo. De aquí la exigencia fenomenológica de volver a las cosas mismas, de volver a este mundo para interrogarnos, en primer lugar, por el sentido de nuestro cuerpo sensible y, en segundo lugar, por el sentido de este mundo en donde vivimos, nos movemos y somos. Mundo en donde el agua es dulce, los árboles frondosos, el cielo, a veces, triste por su gris y, a veces, alegre por su azul, y el cantar de los pájaros verdaderas armonías para nuestros oídos. Un mundo del cual hayan desaparecido las cualidades sensibles o emotivas es un mundo no sólo inhabitable, sino también sin sentido. En un mundo tal, el besar de los amantes se reduciría a un bombardeo de partículas o a simples reacciones físico-químicas. Y un beso desprovisto de intencionalidad, emociones, sensaciones, no sólo es abstracto sino también irreal y, por lo mismo, privado de todo sentido.

\section{4 ¿Es el cuerpo humano un compuesto biológico ${ }^{14}$}

La primera disciplina agregada a la física es la química. Ésta nace cuando la constitución de la materia -inerte y vital- es expresada a partir de leyes cuantitativas. De esta disciplina se desprende la bioquímica y luego la biología, es decir la ciencia de la vida. De la biología general se pasa a la biología humana, cuyo capítulo más importante es la fisiología del cerebro humano.

El especialista en biología humana confirma los valores de la subjetividad y trata de explicarlos como propiedades que emanan de la materia. Concibe al hombre como un ser distinto del animal porque su cerebro es cuantitativamente más complejo. Las cualidades de la materia humana se deben a dicha complejidad. Por consiguiente, la dualidad entre cuerpo y alma queda superada.

La energía nerviosa es la producción y el intercambio de ondas eléctricas de origen químico. El funcionamiento psicológico no sur-

14 Cf. Paul Chauchard, "Las ciencias biológicas y el ateísmo”, El ateísmo contemporáneo, Vol. I, Tomo I, Facultad Filosófica de la Universidad Pontificia Salesiana de Roma (Cristiandad: Madrid, 1971) 513-533. 
ge de una modalidad especial de energía. No obstante, a pesar de que la onda eléctrica que produce el flujo nervioso puede ser captada por los oscilógrafos, la célula no es una imagen exacta de una máquina. Ella posee algo que la hace diferente, tiene caracteres propios. El fenómeno eléctrico es análogo al fenómeno nervioso y no a la inversa como comúnmente suele representarse.

Si bien en el hombre todo funcionamiento puede ser leído a partir de leyes cuantitativas físico-químicas, se puede hacer esto bajo una modalidad especial y específica. El ácido nucleico es el que dirige dicha especificidad y especialidad del ser humano. Éste es producto de esa prodigiosa complejidad y organización de las moléculas cerebrales.

La biología materialista afirma que la vida se funda únicamente en los poderes de los ácidos nucleicos. El funcionamiento vital del hombre consiste en intercambios energéticos y estructuras espacio-temporales de una materia cuyos constitutivos se renuevan incesantemente y cuya arquitectura es lo único que se mantiene: todo es dinámico y funcional. Por tanto, el psiquismo humano, al que los dualistas llaman alma, no es más que la función de un cerebro más desarrollado.

La biología humana nos obliga a reconocer un materialismo dinámico y funcional en el que el pensamiento es indisoluble del cerebro. Pero, a su vez, también nos lleva a reconocer el misterio que entraña la materia humana; misterio que la ciencia reconoce en los enigmas del cuerpo humano.

Este enfoque nos muestra al hombre como una unidad, como una totalidad. El cuerpo está constituido por una materia, pero esa materia difiere de todas las demás porque posee un "principio de organización” que le es connatural. Dicho "principio de organización” es lo que los fenomenólogos denominan subjetividad. El hombre no sería capaz de decidir libremente si su principio ordenador de la materia no fuera una verdadera subjetividad. Por consiguiente, la libertad se convierte en la propiedad fundamental del cerebro humano.

En síntesis, el hombre no es meramente un compuesto biológico determinado a priori por las leyes rígidas de la materia. Por el contrario, es el ser capaz de sobreponerse a su materialidad y darle un sentido inédito a su existencia a partir del principio ordenador de su materia, es decir, a partir de su subjetividad. Sin llegar a desconocer los aportes valiosos de la biología, consideramos que hay una serie de problemas que no encuadran dentro de su enfoque y se salen de su competencia. La biología plantea problemas que sobrepasan su razón de ser. Lo que localizamos en el cerebro son los centros de ejecución motriz o de recepción sensorial pero no los productos de éstas. ¿Cómo explicar los actos y actitudes humanas inmateriales -pensamientos, sentimientos, emociones- a partir de la materia?

La fenomenología ha buscado dar respuesta a algunos de estos problemas, pero lo ha hecho teniendo en cuenta la advertencia de Husserl: "los científicos del espíritu no deberían conformarse en considerar el espíritu como espíritu, sino que deberían retroceder a los fundamentos corporales y elaborar sus explicaciones con la ayuda de la física y de la química”"15.

El "principio de organización" no se agota en su materialidad. Su esencia se manifiesta sobre todo en sus producciones que, paradójicamente, son inmateriales. Razón por la

15 Edmund Husserl, Erste Philosophie I, Husserliana VII (Haag: Martinus Nijhoff, 1956) 325. 
cual, para acercarnos más a la esencia del ser del hombre, consideramos necesario explicitar el desempeño de la corporeidad humana en el mundo de la vida.

\section{Visión fenomenológica acerca del ser del hombre}

\subsection{El cuerpo humano en el mundo de la vida}

En el mundo de la vida realizo una doble experiencia de mi ser: experimento ser verdaderamente corpóreo y experimento una cierta trascendencia de mi dimensión corporal. Estas dos experiencias constituyen el fundamento de mi persona.

Me identifico con mi cuerpo en cuanto existo mi cuerpo: sin mi cuerpo sería nada. $\mathrm{Mi}$ cuerpo está situado aquí y ahora. Con relación al ahora soy siempre presencia. Con relación al aquí estoy dotado de características físicas. Por consiguiente, mi cuerpo me asegura un lugar en el mundo y en el tiempo, y, siendo cuerpo, le doy sentido a los cuerpos que me rodean. Mi cuerpo percibe, tiene hábitos, es instintivo, es sexuado, es emotivo y afectivo. Mi cuerpo conoce el mundo y sabe desenvolverse en él. Mi cuerpo es expresivo y comunicativo. En suma, mi cuerpo es la presencia de mi ser personal ante el mundo.

Pero también experimento situaciones donde mi cuerpo deja de ser el protagonista y se convierte en una especie de "espectador pasivo”. Observo que cuando reflexiono y juzgo mis experiencias corpóreas, experimento una cierta trascendencia de mi cuerpo. Esto me lleva a decir que los hechos no entrañan la totalidad de mi ser personal. Gracias a la conciencia que poseo de experiencias pasadas, esbozo el futuro y me concibo como un ser histórico, como un proyecto, donde el espacio y el tiempo van más allá o más acá del presente inmediato. Así, puedo darle un sentido mediato a mis experiencias inmediatas.

Por otra parte, cuando entro en relación con otras personas, también comprendo que mi cuerpo no muestra la totalidad de mi ser. Me doy cuenta que además de expresar lo que soy, también puedo mentir, fingir o encubrirme en mi cuerpo. Sé que la mirada del otro, aunque a veces descubra actitudes mías que ni yo mismo logro percibir, no abarca la totalidad de mi ser. En el encuentro con el otro, descubro que no soy el único en el mundo. El mundo no es sólo mío sino compartido. En él los significados se entrecruzan, complementan, enriquecen. Mi yo, aunque es único e irrepetible, comparte muchos significados de mundo con los otros.

Mi experiencia personal de identificación y trascendencia corporal se me presenta como materia prima para filosofar. Con base en ella puedo darle sentido y valor a mi realidad. Así descubro mi verdad. Pero mi verdad no es estática, ella se dinamiza y enriquece en la medida en que entra en diálogo con la verdad de los otros. Gracias al encuentro de mi verdad con la verdad del otro amplío el horizonte de mi pensamiento y, por ende, el horizonte de la verdad misma.

Las experiencias de identificación y reflexión son las que trataré de explicitar en los siguientes apartados.

\subsection{El cuerpo como expresión de una subjetividad}

La visión fenomenológica del hombre nos invita a poner en juego nuestra propia existencia de hombres en el mundo. La existencia precede a la esencia. Al hablar de existencia hacemos referencia implícita al cuerpo. La esencia se afirma en la existencia corporal y no al contrario como lo tratan de hacer los enfoques reduccionistas que definen al hombre como una realidad acabada: cár- 
cel, animal, máquina, compuesto biológico. Todos estos seres guardan alguna relación con el ser del hombre pero no lo definen en absoluto. El error de dichos enfoques radica en que definen al ser del hombre como un objeto que puede ser explicado y demostrado "desde afuera". Nuestra experiencia de hombres nos muestra que, paradójicamente, somos nosotros quienes creamos los esquemas conceptuales pero, a la vez, no nos dejamos encuadrar bajo ninguno de ellos, ya que siempre nos mostramos como una realidad inacabada. Lo que las ciencias positivas explican de la corporeidad humana no se refiere a mi cuerpo en tanto sujeto, sino al cuerpo en tanto objeto.

Por consiguiente, la pregunta por el ser del hombre no debe ser formulada en términos de "qué es el hombre" como si fuera un "algo" ya acabado, sino en términos de "cómo es el hombre" teniendo en cuenta que es un "alguien" cuya esencia entraña siempre a un sujeto abierto a sus posibilidades. Esto nos lleva a decir que la esencia del ser del hombre no puede ser explicada y demostrada, sino mostrada y explicitada a partir de las posibilidades y realizaciones humanas en el mundo de la vida: "el cuerpo propio es una permanencia del lado de mí; nunca está verdaderamente delante de mí como objeto, no puedo desplegarlo bajo mi mirada. El cuerpo propio se queda al margen de todas mis percepciones, está conmigo"16.

La existencia nos muestra al ser del hombre como una totalidad significativa; una realidad dinámica que consiste en significar. Dicha totalidad entraña una diversidad que consiste no en diferentes vidas, realidades o sustancias, sino en diversos modos de ser de una misma vida. Una persona puede asumir diferentes roles y funciones permaneciendo y siendo ella misma. Estos modos de ser va- rían según la actitud u orientación que asumamos como sujetos corpóreos frente a nuestras posibilidades. Así, podemos hablar del yo-unidad como el soporte de los diversos modos de ser hombre: yo-organismo, yo-instinto, yo-perceptivo, yo-trabajador, yo-reflexivo, yo-social, yo-trascendente.

La experiencia humana nos muestra el ser del hombre como un ser indivisible que establece sus relaciones con el mundo siendo cuerpo: el cuerpo humano es la expresión de una subjetividad; es la manifestación de su ser personal. En este orden de ideas podemos concebir el cuerpo humano como:

i) El camino de acceso al mundo de las cosas

ii) El órgano de percepción

iii) El "punto cero" a partir del cual organizamos el mundo

iv) El órgano transformador de la realidad

v) El órgano de reconocimiento, comunicación y socialización con los otros sujetos

vi) El órgano axiológico

vii)El fundamento, condición y posibilidad de la creación de cultura.

\subsection{El cuerpo humano como el camino de acceso a las cosas}

Como hombres somos seres situados en la naturaleza, pero nuestra ubicación difiere a la que tienen las cosas porque nosotros estamos abiertos al mundo de las cosas. Esta apertura nos permite dar sentido y significado tanto a nuestra existencia como a la de la naturaleza misma. Gracias a esta facultad, la naturaleza deja de ser una realidad cruda para convertirse en un mundo de significados. La tarea de la fenomenología consiste en mos-

${ }_{16}$ Maurice Merleau-Ponty, Fenomenología de la percepción, trad. Jem Cabanes (Barcelona: Península, 1975) 108. 
trar la relación intrínseca que se da entre sujeto y mundo, es decir, el enlace recíproco entre hombre y naturaleza significada.

La presencia del hombre en el mundo comporta dos modos dinámicos de existencia: la situación -estoy en el mundo- y la intencionalidad u orientación -soy consciente en el mundo.

El hombre es situación en cuanto es un ser que posee un aquí y un ahora propios. La situación nos muestra al mundo no como una sumatoria caótica de cosas, sino como el sistema de significados que establecemos con las cosas por medio del cuerpo propio. La estructura del cuerpo condiciona las posibilidades de experimentar el mundo, determina la zona de nuestras operaciones posibles, la amplitud de nuestra vida. Un ciego o un sordo experimentan el mundo de un modo distinto a como lo haría un sujeto normal. Ellos crean un sistema de significados "especiales” donde sus posibilidades están determinadas por su corporeidad. En el caso de Beethoven, por ejemplo, los significados auditivos fueron reemplazados por los táctiles, los cuales tuvieron que especializarse debido al condicionamiento de su corporeidad.

El mundo se nos revela, y nosotros, siendo cuerpo, le damos sentido, significado. La situación y la intencionalidad nos llevan a afirmar que de hecho existen muchos mundos humanos. El amor, la ciencia, la filosofía, la religión son orientaciones posibles. A partir de ellas podemos percibir el mundo y crear distintos productos culturales: mundo científico, técnico, religioso, filosófico. Todos estos mundos humanos tienen como tela de fondo el mundo de la vida. Éste nos es común y revela muchos más significados que todos los anteriores. Más aun, es la fuente de donde emergen todos, ya que en él es donde el cuerpo propio se encuentra en permanente contacto con las cosas.

\subsection{El cuerpo humano como órgano de percepción}

Nos comunicamos con el mundo cuando el cuerpo actúa como órgano de percepción efectiva. Las percepciones son relaciones de sentido que establecemos con el mundo. Éste se nos muestra como el horizonte en donde las cosas se revelan o se ocultan según la intencionalidad adoptada. Una obra de arte se revela o se oculta según la orientación de nuestra percepción. Podemos ser videntes o ciegos ante una pintura como Las Meninas, por ejemplo. De nuestra percepción orientada depende la valoración o la indiferencia ante las cosas.

La percepción es el saber experiencial que el cuerpo va adquiriendo a lo largo de la vida. Este saber se nos muestra como un fenómeno unitario y original. Es unitario porque la experiencia perceptiva se nos ofrece de golpe, inmediatamente. Las distinciones del tacto y de la vista son desconocidas en primera instancia. Lo que nos enseña a distinguir las percepciones de nuestros sentidos es la reflexión. La afirmación de que poseemos cinco sentidos y de que cada uno funciona como un mundo independiente sin comunicación con los demás, contradice el fenómeno unitario de la percepción. Percibimos de un modo indiviso con nuestro ser total. Aprehendemos la estructura única de la cosa mediante una única forma de existir que relaciona, a la vez, todos los sentidos ${ }^{17}$. Expresiones donde se conjugan percepciones cruzadas de varios sentidos confirman lo dicho: colores cálidos, fríos, chillones, duros; soni-

17 Cf. Maurice Merleau-Ponty, Sentido y sin-sentido, trad. Marcis Comadira (Barcelona: Península. 1977) 89-90. 
dos claros, rugosos, brillantes; perfumes penetrantes, dulces.

La experiencia perceptiva es original porque es la primera operación corporal que ejecutamos para aprehender el significado de las cosas. La percepción no es un mosaico de datos sensoriales que al ser analizados o asociados a comportamientos (pensamientos, deseos, sentimientos, emociones) nos darían como resultado el sentido o la significación: la experiencia perceptiva es conocida mucho antes que la reflexiva. Es un anacronismo considerarla como secundaria ${ }^{18}$. La significación que aprehendemos en el acto perceptivo es preconceptual. Antes del yo pienso que percibo está el yo percibo. Percibir es vivir, y vivir es conocer. En otros términos, la percepción antecede a la palabra y a la re-presentación; la comunicación corporal antecede al lenguaje verbal. Más aun, el lenguaje verbal es consecuencia de la comunicación corporal. No es gratuito que los niños, por ejemplo, comprendan los gestos y las expresiones fisionómicas mucho antes de ser capaces de re-presentarlas por su cuenta o de verbalizarlas: la toma de conciencia de la palabra como región original es naturalmente tardía ${ }^{19}$.

La percepción constituye el fundamento de las experiencias conceptuales. Antes de la conciencia reflexiva se da de hecho la conciencia perceptiva. Esto no significa que la percepción sea de carácter irracional ni que sólo llegue a ser racional a partir de la reflexión. La percepción es una especie de "sabiduría cotidiana”. El cuerpo propio, al estar en constante contacto con el mundo, "sabe" más del mundo que la propia reflexión. Los objetos que percibimos son percibidos y pensados a la vez.
La reflexión no es un saber distinto, sino un saber con un mayor grado de explicitación. Ésta rompe con la familiaridad que ejerce el cuerpo con el mundo y trata de mostrar este saber corporal desde cierta distancia y a partir de cierto asombro o extrañamiento. La tarea de la reflexión es educativa. Con base en ella podemos organizar, afirmar o reorientar nuestras experiencias perceptivas según fines más discernidos y plenificantes para el ser personal de cada uno.

En síntesis, la experiencia perceptiva se nos muestra como la primera certeza del mundo. De tal manera que, si dudamos de la percepción, implícitamente estamos dudando de la reflexión; lo cual nos llevaría a un escepticismo insalvable. La ilusión, de la cual puede ser presa nuestra percepción, tiene como referente primigenio una percepción verdadera: no puedo tener la idea de una ilusión si antes no he experimentado efectivamente la idea de certeza.

\subsection{El cuerpo humano como “punto cero" a partir del cual organizamos el mundo}

El hombre es un ser situado en el mundo. Dicha situación comporta un carácter original distinto al de las cosas y los animales. Las cosas son siempre presentes. Los animales viven el tiempo de forma cíclica. El hombre, en cambio, es presencia temporal, es decir, su estructura esencial es la temporalidad. Las vivencias que conforman nuestra experiencia no son un caos de actos desligados unos de los otros. Ellas conforman una estructura unitaria en donde pasado presente y futuro convergen: no somos sólo lo que somos sino también lo que hemos sido y lo que seremos. Por esta razón, el ser del hom-

18 Cf. Merleau-Ponty, Sentido..., 100.
19 Cf. Merleau-Ponty, Fenomenología ..., 191. 
bre está abierto a todos los espacios y todos los tiempos; gracias a su estructura espaciotemporal, el hombre es el único ser que puede adaptarse a la diversidad de climas y dietas del mundo.

Partiendo del cuerpo propio como "punto cero”, podemos organizar el mundo. Mi cuerpo hace que haya un lejos y un cerca, un alto y un bajo, un arriba y un abajo, un lado derecho y uno izquierdo, un antes y un después, una ausencia y una presencia. No obstante, el cuerpo propio no es estático sino dinámico. Mover el cuerpo significa apuntar hacia las cosas y reorganizarlas de forma distinta. $\mathrm{Al}$ responder a la solicitud que ejercen las cosas sobre nosotros, el mundo se vuelve a organizar de otra manera. Si me desplazo, organizo el mundo desde otro aquí y otro ahora y, a la vez, conservo la experiencia del antes y del allá. A esto se le suma la contemplación de la posibilidad de ejercer nuevos desplazamientos, de anticiparme a futuras presencias: cada presencia capta paso a paso, a través de su horizonte de pasado, presente y futuro, la totalidad del tiempo posible. Así, supera la dispersión de los instantes y puede reintegrar el pasado a la experiencia personal ${ }^{20}$.

A partir de esta estructura espacio-temporal, podemos afirmar que la experiencia corporal se desarrolla teleológicamente, esto es, como inclinación y tendencia continua hacia la aprehensión de las cosas como fenómenos unitarios, como flujo de momentos diferentes de un mismo tiempo. Las percepciones del oído, por ejemplo, no son formas desligadas en el tiempo. Una melodía no la percibimos como una suma de notas, sino como una totalidad en donde cada nota cuenta por la función que ejerce en el conjunto. La percepción del conjunto es más primitiva que la de los elementos aislados. La percepción analítica, que nos muestra los elementos aislados, corresponde a la actitud tardía de la reflexión. La percepción espontánea se da como una unidad temporal.

El yo-reflexivo parte del pasado real, de la experiencia de la percepción espontánea y nos brinda la posibilidad de situaciones futuras, convirtiéndonos de paso en seres responsables de nuestra propia historia. La tendencia del cuerpo propio hacia la racionalidad es una invitación permanente de pasar del "punto cero" a puntos más elaborados; de pasar de la experiencia vivida a la experiencia reflexionada.

El “punto cero” es fundamento, pero él no agota la totalidad del ser del hombre. Los hábitos estables que se dan de forma impersonal pueden ser rotos y explicitados a partir de la reflexión. La experiencia reflexiva puede llevarnos a conquistar nuevas situaciones en las que los hábitos, las costumbres y hasta los instintos, en vez de esclavizarnos, estén al servicio de nuestros intereses y metas.

En la dinámica de la experiencia vivida y la reflexión personal, podemos concebirnos como proyectos que tienden hacia la autorealización. El proyecto personal nos exige pasar de lo que tenemos como condición a lo que apuntamos por opción; de lo que somos a lo que tenemos intención de ser; de la impersonalidad a la personalidad. De esta manera, la persona se engrana en la situación y, a partir de ella, puede llegar a fundirla en su proyecto: el lazo que une al cuerpo humano con el mundo es, al mismo tiempo, el medio de su libertad. Se trata de comprender cómo el hombre sin quebrantar sus condicionamientos, sino al contrario utilizándolos, proyecta alrededor los instrumentos

20 Cf. Merleau-Ponty, Fenomenología ..., 103. 
de su liberación, constituyendo un mundo cultural en el que el comportamiento natural sea convertido en humano ${ }^{21}$.

\subsection{El cuerpo humano como órgano transformador de la realidad}

La apertura del cuerpo humano nos muestra al hombre como un ser que, además de estar situado, posee la capacidad de crear nuevas situaciones. Esto nos lleva a decir que el cuerpo humano es un cuerpo fenomenal que está abierto a aprehender las cosas como fenómenos y a usarlas como medios para lograr fines o tareas. A esto debemos agregarle la capacidad que también poseemos de proyectar el cuerpo propio anexándole nuevos instrumentos que nos permitan cambiar la realidad. Así, el cuerpo humano se nos muestra como principio de dominio de la naturaleza y como principio de instrumentación.

Como principio de dominio, el hombre puede intervenir la naturaleza para transformarla y ponerla a su servicio. El poder de manipulación figura como la expresión más evidente de la capacidad transformadora del cuerpo humano. El hombre, siendo mano, trabaja, actúa y lucha en relación con las cosas. En virtud de esta capacidad, nuestra referencia al mundo no es sólo de conocimiento sino también de transformación. El mundo se nos muestra manipulable gracias a que nuestra estructura corporal lo permite. En la medida en que reorganizamos el mundo siguiendo nuestros intereses o necesidades, proyectamos sobre él un sentido original, $\mathrm{y}$ de paso lo humanizamos.

Siendo manos, el hombre ha ido conociendo y transformando el mundo a lo largo de la historia. Las noticias que nos llegan del hom- bre primitivo han sido fruto de obras manuales: pinturas rupestres, piedras talladas, utensilios...; el conocimiento del mundo se ha perfeccionado a través del tiempo, hasta llegar a ser lo que hoy denominamos como técnica y tecnología.

En cuanto al principio de instrumentalidad, vemos que el cuerpo propio es el fundamento de todos los instrumentos. Un instrumento es una cosa material que ha sido humanizada para realizar un fin determinando, y una vez utilizado puede ser desechado o mejorado. Por tal motivo, el cuerpo humano no puede ser concebido como un instrumento, porque jamás podemos abandonarlo: el cuerpo humano es la raíz de la instrumentalidad, ya que todos los instrumentos existen en virtud de un cuerpo que está en disposición de utilizarlos ${ }^{22}$.

Las creaciones del hombre, como la técnica y la tecnología, no son fines en sí mismos, sino medios. Por consiguiente, deben ayudar a la dignificación y a la realización integral de la humanidad. No como pasa en el reino de la tecnocracia donde el hombre deja de ser un fin para ocupar el lugar que le corresponde al instrumento; de esta forma, el hombre va en contra de su esencia, y la instrumentalización y deshumanización comienzan a hacer carrera.

Los instrumentos son la extensión de las posibilidades del cuerpo humano: la lente del ojo, el audífono del oído, la retroexcavadora de la mano, el computador del cerebro. Sin embargo, todos ellos se refieren al cuerpo como al arquetipo que los evalúa y supera. El hombre se procura instrumentos porque sabe que su ser es limitado y débil frente a los ambiciosos proyectos que planifica. No podemos reducirnos a la labor de nuestros

21 Cf. Merleau-Ponty, Sentido ..., 20.

22 Cf. Joseph Gevaert, El problema del hombre: Introducción a la antropología filosófica, trad. Alfonso Ortiz (Salamanca: Sígueme, 1987) 102. 
cuerpos porque las obras pensadas, deseadas o necesitadas sobrepasan inmensamente nuestra estructura corporal. Nuestra reflexión, el volver sobre las experiencias vividas, nos permite concebir mejores modalidades de trabajo para llevar a cabo los objetivos proyectados. Es por esta razón que, día tras día, creamos mejores medios artificiales que prolongan nuestras fuerzas y amplían nuestro campo de ejecución.

\subsection{El cuerpo humano como órgano de reconocimiento, comunicación y socialización con el otro}

Además de dar lugar a nuestra existencia particular, el cuerpo propio nos inserta en un mundo donde existen otros sujetos corpóreos: el mundo intersubjetivo. En éste, mi cuerpo existe para el otro y el cuerpo del otro existe para mí.

La intersubjetividad tiene como punto de partida la intercorporeidad. El reconocimiento del otro es, en primera instancia, un hecho perceptivo. La concepción del cuerpo propio como expresión de mi subjetividad me conduce necesariamente hacia el reconocimiento del cuerpo ajeno como expresión de una subjetividad distinta, diversa. La intersubjetividad en tanto intercorporeidad es un hecho que goza de evidencia plena. Siendo percepción distinguimos de inmediato otros cuerpos expresivos, esto es, otras fuentes de sentido, de significación, que comparten con el cuerpo propio un mundo común.

El ser personal es único e irrepetible, pero los significados del mundo particular están permeados por todas partes de los significados de otros seres personales. La manera como percibimos y el lenguaje que utilizamos siempre lleva una huella que trasciende nuestra existencia personal. El mundo de la existencia no es ni mío ni tuyo, sino nuestro. Esto nos lleva a afirmar que la existencia propia es esencialmente una co-existencia.

El cuerpo humano es una huella parlante. Sabemos por experiencia que las vivencias van acompañadas de gestos corporales. El comportamiento humano no es solamente un estado interior, sino también expresiones corporales externas que se brindan a los demás como un lenguaje genuinamente humano. Experiencias como las del amor o el odio se manifiestan como estados interiores y también como gestos corporales; por lo cual son accesibles a la percepción del otro. Son tipos de comportamiento que pueden verse desde afuera, existen sobre un rostro o sobre unos gestos ${ }^{23}$.

En el mundo de la vida, el cuerpo propio, además de estar abierto al mundo de las cosas, también lo está al de los demás. El otro no se nos presenta como un pensamiento objetivo, sino como una evidencia corporal. Yo experimento la visión del otro no como un pensamiento de ver sino como una mirada capaz de organizar el mundo desde su centro personal. Gracias al otro, nuestro ser conoce y amplía su radio de experiencias y posibilidades: las observaciones que hago sobre experiencias como el amor o el odio, por ejemplo, son observaciones que aprendo a partir del cuerpo de los otros, ya que yo no puedo ser testigo de ese comportamiento en el momento de experimentarlo. La vivencia espontánea de estas experiencias se me escapa porque yo soy ellas en el momento de realizarlas. Paradójicamente, podemos pensar la ira en el momento de calma, y referirnos a ella sólo en la vivencia de una ira ajena. Tal vez mediante el análisis formal podamos pensar al hombre como un ser solitario, pero la experiencia vivida nos mues-

${ }^{23}$ Cf. Merleau-Ponty, Sentido ..., 96. 
tra la imposibilidad de este hecho. El hombre no es un ser solitario que vive en un mundo de cosas, sino un ser solidario que vive en un mundo cultural intersubjetivo.

El mundo cultural indica que yo y los otros gozamos de una misma estructura común y que ambos, a partir de la realidad primigenia de la corporeidad, podemos comprender, transformar y mejorar las acciones depositadas en la naturaleza por el género humano a lo largo de la historia. En la relación con los otros es donde la existencia particular hunde sus raíces, encuentra una prolongación de sus intenciones y una manera familiar de tratar con el mundo: con el otro se da un ser a dos, en donde las múltiples perspectivas se entrecruzan unas con las otras para dar razón de un mismo mundo común ${ }^{24}$.

Todo tipo de comunicación humana, ya sea gestual o verbal, halla en la estructura del cuerpo humano su fundamento, condición y posibilidad. El gesto y la palabra, para ser expresivos y comunicativos, parten del hecho de que deben ser ejecutados y percibidos por un cuerpo humano.

La estructura común de nuestra corporeidad, anteriormente mentada, no implica que la visión propia sea la visión única del mundo. La experiencia nos muestra que existen muchas perspectivas, las cuales constituyen las bases de los diversos mundos culturales. No hay una visión única del mundo; sin embargo, vemos que es fácil que un sujeto, ya sea personal o cultural, considere su visión de mundo como la única. Así, dicho sujeto priva a los demás de la riqueza de posibilidades contenidas en su propio ser, y reduce su mundo y el de los demás a las estrechas dimensiones del campo de su interés.
Nuestra experiencia corpórea nos conduce hacia dos momentos esenciales en la concepción del hombre: la afirmación de la subjetividad propia y el reconocimiento de la subjetividad de los otros. En el momento en que reconocemos la experiencia como propia, nos abrimos a todo lo que no es "yo", somos sensibles al mundo y a los demás. Nuestra vida se nos muestra como individual y, a la vez, universal ${ }^{25}$.

Dichos momentos esenciales -la afirmación y el reconocimiento- nos abren la posibilidad de un encuentro, un diálogo entre sujetos corpóreos. La multiplicidad de orientaciones o formas de ver el mundo, no imposibilitan el encuentro intersubjetivo. El cuerpo humano, en tanto intersubjetivo, siempre está abierto a crear nuevas y mejores situaciones; nuevas maneras de humanizar un mundo que nos es común.

Además de la apertura que el cuerpo propio tiene hacia los otros, cabe decir que también está abierto a lo Infinito. En el mundo de la vida, esta orientación amplía esta intersubjetividad y nos puede mostrar lo Infinito como un ser personal que comparte y, a la vez, trasciende la existencia. Es decir, el hombre puede experimentarse a sí mismo, a los otros y a las cosas en relación con Otro Eterno. La experiencia religiosa es también un modo de ser en el mundo con otros. Dicha manera de ser es significativa en la medida en que el hombre experimente a Dios no como un pensamiento abstracto, sino como una vivencia que lo interpela hasta en sus actitudes y comportamientos más íntimos. En la vivencia de Dios, el hombre hace participar al ser supremo en su proyecto, ve enriquecidas sus posibilidades y encuentra el sentido primigenio de su existencia.

24 Cf. Merleau-Ponty, Fenomenología ..., 354.

25 Cf. William Luypen, Fenomenología existencia, trad. Pedro Martín (Buenos Aires: Carlos Lohlé, 1967) 45-47. 
En la orientación hacia Dios, el cuerpo propio juega un papel fundamental, ya que la comunicación con el Tú Eterno parte de dos experiencias corporales esenciales a todas las expresiones religiosas: la manifestación en la historia, por parte de Dios; y la contemplación de ese Dios manifestado por parte del hombre. La diversidad de actitudes y expresiones rituales experimentadas en la orientación a Dios se inscriben en este campo.

\subsection{El cuerpo humano como órgano axiológico}

El espacio vital del hombre no es un hábitat cerrado, sino un mundo de significados abierto. No obstante, nuestra condición humana nos dice que somos seres finitos; que nuestro cuerpo es limitado; que frente al horizonte de posibilidades que nos brinda el mundo, no podemos responder de una vez por todas, que se nos hace necesario establecer una jerarquía de valores para poder organizar la invasión de percepciones que nos vienen del mundo. Nuestra existencia es paradójica porque, a la vez, se nos muestra como infinitud de posibilidades y como finitud de experiencias.

La apertura corporal permite en nosotros una multiplicidad de sensaciones que debemos reducir para ponerla acorde a nuestras capacidades. En virtud de esta reducción podemos realizar las creaciones culturales. En otras palabras, la apertura al mundo, al no brindarnos ningún punto de referencia natural a partir del cual las cosas estén fijamente estructuradas, nos impulsa a canalizar el caudal de sensaciones a través de nuestros sentidos y sus extensiones. Así, descargamos todo el material sensitivo que nos abruma y, poco a poco, vamos incorporando sólo el residuo de sensaciones que más valoramos, es decir, que más significado tienen para nosotros: la apertura al mundo es una carga. El hombre está sometido a una sobreabundancia de estímulos, a una plétora de impresiones sin finalidad, que afluyen a él y que él tiene que dominar de alguna manera para poder vivir humanamente. La carga directa e inmediata que produce la multiplicidad de sensaciones tiene que ser transformada en una oportunidad para existir ${ }^{26}$.

Los significados que se derivan de las diversas sensaciones poseen un valor cultural muy rico y riguroso: la vista puede ser asociada a la razón o a la brujería; el gusto puede servir de metáfora para el refinamiento estético o para la experiencia sexual; un olor puede significar santidad, poder político o exclusión social $^{27}$.

El residuo de la valoración del amplio caudal sensorial, se va constituyendo con el tiempo en el paradigma perceptivo de tal o cual cultura. Los miembros que la componen, partiendo de esta base, pueden llegar a traducir esta experiencia en conceptos o representaciones. El paradigma sensorial propio de cada cultura se nos muestra como el modelo básico a aprender. Después de un largo proceso de apropiación y madurez, el ser personal puede criticarlo, resistirlo o enriquecerlo.

Por consiguiente, la percepción humana es un proceso de valoración y de aprendizaje cultural. Los sentidos educan, y sus expresiones se aprenden. El modelo sensorial adoptado por una cultura revela sus aspiraciones, preocupaciones, divisiones, jerarquías e interrelaciones: los sentidos enmarcan la experiencia perceptiva según orientaciones y valoraciones personales o culturales ${ }^{28}$.

26 Cf. Gehlen, El hombre ..., 40.

27 Cf. Constance Classen, Fundamentos de una antropología de los sentidos (online) 2, consultado en 30/06/ 00, disponible en: <http:/www.unesco. org./issj/rics153/classenpa.htlm)>.

28 Cf. Merleau-Ponty, Fenomenología ..., 232-233. 
Según el modelo sensorial adoptado, podemos decir que existen culturas visuales, orales, táctiles... La cultura occidental ha adoptado el paradigma perceptivo visual. Ésta ha considerado que el sentido de la vista es principal, ya que está estrechamente relacionado con la racionalidad.

\section{La cultura occidental: una cultura visual}

La primacía del sentido de la vista se observa ya en la mitología clásica. Edipo, después de ver la crudeza de su realidad, opta por sacarse los ojos. De esta manera, se cegó no sólo al mundo de las cosas, sino también a su proyecto de vida. Este acto significó para Edipo reducir la existencia a su mínima expresión.

Este legado cultural pasó a la filosofía. Los pensadores clásicos consideraban a la vista como el sentido por excelencia, pues él nos revela la presencia de las cosas ${ }^{29}$. Para Platón, la razón constituye "los ojos del alma”. Idein, de donde viene la palabra idea, significa "ver no sensible”. Idea significa "lo visto por el alma”. Y así como el ver sensible necesita de la luz natural, el ver racional necesita de la luz del Ser. El mundo de las ideas es visual, es un mundo de figuras contempladas ${ }^{30}$.

Aristóteles también se rige por la hegemonía del sentido de la vista. Esto le permite desarrollar una filosofía inspirada en imágenes y objetivaciones del mundo. Él, una vez construido su esquema conceptual-visual, fue intercalando los demás sentidos. Así, com- prendió al hombre desde la visión del ser, pero no al ser desde la visión del hombre ${ }^{31}$.

La cultura occidental acentuó más el sentido de la vista, en cuanto a su importancia cultural, cuando la asoció al floreciente campo de la ciencia. En ese momento, la mirada inquisitiva y penetrante del científico, ayudada por las extensiones ópticas como el microscopio y el telescopio, se convirtió en la metáfora de la adquisición de conocimiento ${ }^{32}$.

Las teorías de la evolución también favorecieron la elevación de este sentido al decretarlo el sentido de la civilización. Se supuso que los sentidos inferiores -olfato, gusto y tacto-perdían importancia conforme el hombre ascendía en la escala de la evolución: “existe una jerarquía sensorial de las razas humanas en la que el europeo (el hombreojo) ocupa el peldaño superior, seguido del asiático (el hombre-oído), el amerindio (el hombre-nariz), el australiano (el hombre-lengua) y el africano (el hombre-piel)”33.

En los siglos XIX y XX, la función de la vista se amplió más con la invención de las tecnologías visuales como la fotografía, la televisión, el cine y la informática.

En consecuencia, la preferencia de Occidente por la visión ha permeado sus construcciones culturales en todos sus ámbitos: escritura, pensamiento, tecnología... Por eso, todos los paradigmas sensoriales de culturas extrañas fueron filtrados por la manera visual de percibir el mundo. La escritura, la lectura, los textos se han utilizado como es-

29 Cf. A. Synnott, Puzzling over the senses from Plato to Marx (Toronto: University of Toronto Press, 1991) 3-4. Cit. en Classen, Fundamentos ..., 3.

30 Cf. Danilo Cruz Vélez, Filosofía sin supuestos (Buenos Aires: Sudamérica, 1970) 238-245.

31 Cf. Martín Buber, ¿Qué es el hombre?, trad. Eugenio Imaz (México: FCE, 1954) 23-46.

32 Cf. Classen, Fundamentos ..., 3.

33 S. Gould, The Flamingo's Smile: Reflection in Natural History (New York: Norton, 1885) 204-205. Cit. en Classen, Fundamentos ..., 6. 
quemas fijos en el análisis cultural. Se creía que la cultura de un pueblo es un conjunto de textos que el investigador intenta leer por encima del hombro de sus propietarios. Muchos investigadores no fueron más allá de la descripción e interpretación visual de una cultura ajena. Por eso no se percataron de que existen objetos culturales que pierden toda su significación original si son abstraídos de su contexto dinámico y transformados en objetos estáticos, observables en las vitrinas de los museos o álbumes de fotografías. Hay un sinnúmero de obras de culturas ajenas que son hechas para ser aplicadas por el cuerpo y no simplemente para ser contempladas $^{34}$.

Es evidente que el paradigma perceptivo occidental ha hecho avanzar la cultura humana en medidas extraordinarias. Pero, a la par, también ha llevado a discriminación cultural. Recordemos que los semitas, africanos, amerindios... fueron considerados por los occidentales como prehumanos sin alma porque no compartían con ellos su manera de percibir el mundo. Las culturas estructuradas en otro sentido diferente al de la vista eran concebidas como primitivas o salvajes. Las distinciones raciales -blanco, negro, amarillo, zambo, mestizo...- también se hicieron a partir de sensaciones visuales ${ }^{35}$.

La discriminación de la mujer también estuvo ligada a la percepción. Las mujeres fueron consideradas sólo como aptas para desarrollar sentidos inferiores, y por eso estaban destinadas a ambientes como la cocina, la cama o el cuarto de los niños; mientras que las labores superiores, como la erudición, la aventura y el gobierno, debían ser ejecutadas por el género masculino.

El énfasis visual hace que la explicitaciones o representaciones de la cultura giren en torno a conceptos ópticos: contemplar, imagen, perspectiva, punto de vista, perfil, horizonte, cosmovisión, ideas, ideas claras, reflejo, evidencia, intuición, objeto, sujeto, texto, contexto... También hace que los conceptos derivados de otras experiencias sensoriales vayan siendo sustituidos por conceptos ópticos: armonía de mundo, por visión de mundo; olor a santidad, por aura... Al estructurar esquemas puramente visuales para comprender otras culturas, también se puede pasar por alto que existen culturas que explicitan su modo de percibir el mundo a partir de complejos vocabularios no visuales ${ }^{36}$.

\section{Perspectivas}

Es el momento para hacer una breve síntesis de lo que nuestra reflexión sobre lo percibido nos ha permitido plasmar en el lenguaje como sedimentación de la experiencia humana.

La experiencia nos ha puesto de presente que no tenemos un cuerpo sino que somos cuerpo. Que no pensamos “desde” el cuerpo, ni “con” el cuerpo, ni “a través” del cuerpo, sino que pensamos “como” cuerpo, que pensamos corporalmente; que nuestro cuerpo no es una suma de órganos o sistemas, ni un elemento acompañante de una psiquis con mayor o menor influencia sobre ella.

34 Cf. Classen, Fundamentos ..., 4-5.

35 En el estudio de los sentidos no se halla la prueba de una fase de la evolución, sino claves esenciales sobre la manera como una sociedad crea y plasma un mundo con sentido. Una cultura extraña no puede ser estudiada según el modelo de la cultura propia. Esto significa que se debe descifrar los valores codificados en cada uno de los sentidos. Así, descubriremos un profundo simbolismo sensorial ignorado para poner de manifiesto la jerarquía de valores sensoriales que entraña cada cultura. Cf. Classen, Fundamentos ..., 4-5.

36 Cf. G. Gossen, Chamulas in the world of the sun (Cambridge: Harvard University Press, 1974) 5-25. Cit. en Classen, Fundamentos ..., 7. 
El cuerpo se nos ha hecho presente como intencionalidad no tematizada; como expresión de una subjetividad; como la vía de acceso al mundo de las cosas; como "punto cero" de todas las experiencias; como órgano transformador de la realidad; como órgano de socialización; como órgano axiológico; como apertura originaria al mundo; como un ser no determinado a priori por la naturaleza; como fundamento, condición y posibilidad para crear cultura. De esta manera, el cuerpo humano no es una "adecuación” con lo que hay fuera de él sino un habitar que, al fundamentar la unidad cuerpo-mundo, da origen al significar. La corporeidad es un "saber" consciente sobre el mundo. La sensación corporal no es un comportamiento ciego; ella constituye perceptivamente la significación. Ella no es el contenido de una conciencia sino los modos como la conciencia corporal constituye mundos de significación. La percepción no es la sumatoria o la organización de sensaciones, sino las operaciones de una conciencia corporal que, como el cogito cartesiano, conoce, quiere, desea, rechaza, imagina, siente...

Todo lo anterior nos sugiere que podríamos seguir aplicando el método para poner de presente el significado de la percepción en las distintas creaciones culturales: pintura, literatura, escultura, tecnología, publicidad, cine..., y finalmente en la educación. Queremos aprovechar para detenernos un poco en el tema del "aprender a percibir", o, como decía Merleau-Ponty, re-aprender a ver el mundo, como uno de los objetivos fundamentales de la educación. La percepción no nace, se hace, ya que ella es un proceso cultural de aprendizaje. En virtud de esta posibilidad, nos liberamos de los enfoques deterministas y absolutistas, y nos elevamos, como hom- bres cotidianos, al status de seres capaces de interrogar y de reflexionar con mirada crítica los acontecimientos que giran en torno nuestro. De esta manera, las investigaciones que se creían cerradas y agotadas vuelven a abrirse. La mirada crítica nos devuelve la subjetividad enajenada y nos muestra al mundo como un ser que todavía está por mirar.

Uno de los pocos presupuestos aceptado por los fenomenólogos es el carácter teleológico del ser humano: el hombre es un ser cuyo ser es tener que llegar a ser. Para Husserl, los griegos, al asumir que la existencia no era un destino regido por los dioses o la Naturaleza sino un proyecto, decidieron vivir en "la libre conformación de su existencia, de su vida histórica a partir de las ideas de la razón, en orden a tareas infinitas" ${ }^{37}$. Esta decisión griega se convirtió en el presupuesto justificador del quehacer de la humanidad occidental. El telos espiritual de esta humanidad "en el que viene inserto el telos singular de las naciones y de los hombres individuales, yace en lo infinito, es una idea infinita hacia la que de modo oculto tiende, por así decirlo, a desembocar el devenir espiritual global”38.

El objetivo fundamental de la educación es precisamente conducir al estudiante a aprender a ser y no simplemente a tener. Pero este aprender a ser implica un aprender a pensar, el cual, a su vez, implica un aprender a percibir. ¿Por qué? Porque la sabiduría es tan sólo una utopía, una posibilidad del ser humano. Y la educación tiene que ser una educación para la sabiduría. Tenemos que llegar a ser sabios; es decir, a ser hombres que desde su experiencia de vida estructuran las bases de un mundo cada vez más humano. Esto es posible si nuestro pensar es un regre-

\footnotetext{
37 Edmund Husserl, La crisis de las ciencias europeas y la fenomenología trascendental (Barcelona: Crítica, 1991) 328.

38 Husserl, La crisis ..., 330.
} 
sar mediante la reflexión a lo que se vive y se experimenta en el mundo de nuestro diario vivir, para confrontarlo críticamente con el significado del ser humano y con las normas ideales que deben orientar nuestro trascender.

No es suficiente habitar el mundo para comprenderlo, ya que nuestro mundo no es una unidad fáctica, sino la unidad de sentido que abraza todo el horizonte de nuestro existir. La reflexión sólo será significativa y de alcances existenciales, si hemos realmente aprendido a percibir, superando el percibir ingenuo de la actitud natural que afirma la realidad como lo que se encuentra al frente, como algo autónomo y finiquitado en su ser y en su significado, y que, inclusive, lleva al hombre a pensarse como un simple ente entre los entes del mundo y no como el sujeto del mundo. Gracias al pensar reflexivo, el alumno alcanza la representación cognoscitiva, valorativa, imaginativa $\mathrm{y}$ afectiva de sí y de su mundo. Y eso es posible porque el cuerpo posee la posibilidad de flexionar-se sobre sí y de re-flexionar sobre el mundo. La reflexión y lo irreflexivo son las dos caras del constituir mundos humanos.

Toda educación debe ser crítica y reflexiva. Ella debe capacitar al alumno para interrogar al mundo de la vida en toda su riqueza, teniendo en cuenta que el primer acercamiento a esta interrogación es la percepción entendida no como función sensorial sino como el arquetipo del encuentro originario del hombre con su mundo; encuentro mediante el cual intersubjetivamente le otorgamos o nos apropiamos del sentido que los hombres ya le han dado. Pero los sentidos no son como las cosas que simplemente se encuentran ahí frente a nosotros. Ellos deben ser apropiados y constituidos. Partiendo del mundo de la vida, en el cual todo sentido se origina, el alumno debe aprender a analizar sus vivencias para convertirlas en experiencias conscientes, en experiencias comprendidas, en experiencias puestas en relación con otras, tanto propias como ajenas, para otorgarles continuidad, coherencia y valor. Sólo así pueden contribuir al desarrollo del propio pensamiento y del propio ser.

El aprender a percibir también se hace indispensable, pues sólo él nos permite tomar conciencia de las perspectivas que alimentan al Otro para poder entrar en diálogo con él. Ser cuerpo es estar en el mundo con los otros. Sólo a través del diálogo, del encuentro, facilitado por la percepción, aprendemos a no tener la "Razón”, a no absolutizar nuestros puntos de vista, a convertir los puntos de vista en pensamiento colectivo. Gracias a nuestra posibilidad de percibir, nuestra verdad deja de ser adecuación del sujeto con el objeto para convertirse en un acontecimiento en el que los sujetos se implican entre sí y se implican con el mundo. La verdad sólo acontece en el diálogo, en el encuentro, pues sólo en él se concilian la identidad y la diferencia, la unidad y la diversidad. Sólo en el diálogo, en cuanto impone la importancia de los problemas sobre las soluciones, se desarrolla en el alumno la capacidad de pensar, la cual, a su vez, puede ser definida como el diálogo de la vida (bios) con su mundo, diálogo que implica la palabra, la significación, el sentido.

La tarea del aprender y enseñar a percibir debe hacerse más pronto que tarde porque en aprender a percibir se nos va la vida. 